\title{
COVID-19 in otolaryngologist practice: a review of current knowledge
}

\author{
Joanna Krajewska ${ }^{1}$ (D) Wojciech Krajewski ${ }^{2} \cdot \mathrm{Krzysztof} \mathrm{Zub}^{1} \cdot$ Tomasz Zatoński $^{1}$
}

Received: 30 March 2020 / Accepted: 6 April 2020 / Published online: 18 April 2020

(c) The Author(s) 2020

\begin{abstract}
Purpose Otorhinolaryngological manifestations are common symptoms of COVID-19. This study provides a brief and precise review of the current knowledge regarding COVID-19, including disease transmission, clinical characteristics, diagnosis, and potential treatment. The article focused on COVID-19-related information useful in otolaryngologist practice. Methods The Medline and Web of Science databases were searched without a time limit using terms "COVID-19", "SARSCoV-2" in conjunction with "otorhinolaryngological manifestation", "ENT", and "olfaction".

Results The most common otolaryngological dysfunctions of COVID-19 were cough, sore throat, and dyspnea. Rhinorrhea, nasal congestion and dizziness were also present. COVID-19 could manifest as an isolated sudden hyposmia/anosmia. Upper respiratory tract (URT) symptoms were commonly observed in younger patients and usually appeared initially. They could be present even before the molecular confirmation of SARS-CoV-2. Otolaryngologists are of great risk of becoming infected with SARS-CoV-2 as they cope with URT. ENT surgeons could be easily infected by SARS-CoV-2 during performing surgery in COVID-19 patients.

Conclusion Ear, nose and throat (ENT) symptoms may precede the development of severe COVID-19. During COVID-19 pandemic, patients with cough, sore throat, dyspnea, hyposmia/anosmia and a history of travel to the region with confirmed COVID-19 patients, should be considered as potential COVID-19 cases. An otolaryngologist should wear FFP3/N95 mask, glasses, disposable and fluid resistant gloves and gown while examining such individuals. Not urgent ENT surgeries should be postponed. Additional studies analyzing why some patients develop ENT symptoms during COVID-19 and others do not are needed. Further research is needed to determine the mechanism leading to anosmia.
\end{abstract}

Keywords COVID-19 $\cdot$ SARS-CoV-2 $\cdot$ Otolaryngological manifestations $\cdot$ Olfaction $\cdot$ ENT

\section{Introduction}

At the end of 2019 in Wuhan, a large city in the Hubei Province of China, a novel coronavirus, Severe Acute Respiratory Syndrome Coronavirus 2 (SARS-CoV-2), was considered as the cause of a number of lower respiratory tract infections [1]. On February 11, 2020, the new disease caused by the SARS-CoV-2 virus was officially termed "COVID19" by WHO [1]. The high potential of human to human transmission led to rapid COVID-19 epidemic in China and

Joanna Krajewska

krajewska.jm@gmail.com

1 Department and Clinic of Otolaryngology, Head and Neck Surgery, Medical University in Wroclaw, Borowska 213 Street, 50556 Wroclaw, Poland

2 Department and Clinic of Urology and Urological Oncology, Medical University in Wroclaw, Wroclaw, Poland subsequent global pandemic [1]. On March 30, 2020, a total of 638.146 confirmed cases of COVID-19 and 30.039 deaths were reported by WHO.

\section{Aim of the study}

The main aim of this study was to provide a brief and precise review of the current knowledge regarding COVID-19, including disease transmission, clinical characteristics, diagnosis and potential treatment. The article focused on information that, in our opinion, could be useful in otolaryngologist practice. We emphasized the role of otolaryngologist in rapid COVID-19 diagnosis. We also implied the high risk of becoming infected with SARS-CoV-2 as a results of the practice of the ENT specialist. 


\section{Methods}

The Medline and Web of Science databases were searched without time limit but focusing on the newest report, using the terms "COVID-19", "SARS-CoV-2", "novel coronavirus", and "coronavirus from Wuhan" in conjunction with "otorhinolaryngological manifestation", "ENT", "ear", "nose", "throat', "oral cavity", "pharynx", "larynx", "hearing", "vertigo", "head and neck", and "olfaction". Boolean operators (NOT, AND, OR) were also used in succession to narrow and broaden the search. Auto alerts in Medline were also considered, and the reference lists of original articles and review articles were searched for further eligible sources. Opinions of medical societies were also included if applicable. The search included articles without language limitations.

A total of 1790 articles were originally identified using our search criteria. 1740 articles were excluded after abstract or full-text analysis because they did not exactly address the topic. Therefore, the total number of 50 studies were finally chosen to prepare this manuscript. Studies on which this article was prepared were not limited to large cohorts, as a vast majority of reports were based on small cohorts. Because of COVID-19 novelty, randomized controlled studies and precise recommendations for COVID19 management are not available yet. We presume that even reports based on sparse cohorts could be valuable at this time and may lead to further better disease understanding and treatment.

\section{Origin, transmission, and characteristics of SARS-CoV-2}

Human SARS-CoV-2 express $96.2 \%$ genomic similarity to bats' coronavirus. Because of this high genomic similarity bats have been considered as a natural virus host. Therefore, it was speculated that human SARS-CoV-2 might be transmitted to humans from bats through other mammalian hosts [1].

According to epidemiologic studies, the first human SARS-CoV-2 infection presumably took place in Wuhan's seafood market where live animals were sold [1]. First COVID-19 cases were confirmed in individuals who had previously visited this market [1]. Nevertheless, the following COVID-19 cases were not exposed to this kind of seafood market- related infection. Therefore, a potential human to human transmission was suggested to be the main source of the virus spread [1]. The virus is transmitted between individuals through respiratory droplets that are produced by an infected person while sneezing, coughing or talking and staying in the short distance from another person. Direct contact with a person with COVID19 or a direct contact with the surfaces contaminated with SARS-CoV-2 with subsequent contact with own nasal cavity, oral cavity or eyes are also sources of infection [1]. Oro-fecal transmission of the virus is presumably also possible. It was suggested that the two meters distance between an infected and non-infected person should be enough to avoid infection [2]. Van Doremalen et al. conducted an experimental study in which they reported that SARS-CoV-2 was able to remain viable in aerosols for $3 \mathrm{~h}$ [3]. SARS-CoV-2 survived up to $72 \mathrm{~h}$ on plastic and stainless steel, on copper the virus was not detected after $4 \mathrm{~h}$, while on cardboard no viable virus was found after $24 \mathrm{~h}$ [3].

The incubation time for COVID-19 since the exposure to SARS-CoV-2 is believed to reach 14 days, nevertheless, the majority of patients develop COVID-19 disease after 4-5 days (range between 2 and 7 days) after being infected [4, 5]. COVID-19 remains contagious even during the latency period, thus patients before clinical COVID-19 presentation can transfer the virus to others [1].

It was reported that the median time to no detectable SARS-CoV-2 RNA in oropharyngeal samples in patients with COVID-19 reached 20 days (range between 8 and 37 days) [6]. Samples obtained from patients with a mild or moderate form of the disease more quickly became negative for SARS-CoV-2 than samples obtained from severe COVID-19 cases [6].

\section{Clinical manifestation of COVID-19 - important knowledge for otolaryngologists}

Fever, fatigue and dry cough are considered to be the most common manifestations of COVID-19 [7-9]. Anorexia, dyspnea, sputum production, and myalgias are reported in more than $25 \%$ of cases [7]. Sore throat, rhinorrhea, headaches, nausea, and diarrhea are less frequent and are mainly observed in mild or moderate forms of the disease [7]. Cough, dyspnea, sore throat, rhinorrhea, nasal congestion, throat congestion, tonsils edema, enlarged cervical lymph nodes or dizziness are symptoms that otolaryngologist could encounter while examining patients with COVID-19.

It was recently reported that COVID-19 led to hyposmia/ anosmia and taste disturbances [10]. South Korea, China and Italy presented that a significant number of individuals with COVID-19 was affected by hyposmia/anosmia. A few cases were also detected in Germany, while in South Korea $30 \%$ of infected individuals developed hyposmia/ anosmia. There are also reports implying that COVID-19 may present as isolated anosmia [10]. Researches from various countries observed patients with COVID-19 presenting isolated anosmia, without any other symptoms [10]. They suggested that these individuals could be the hidden carries 
of SARS-CoV-2 as they do not meet the current criteria for diagnosing COVID-19. These patients could be the source of the rapid spread of COVID-19.

Professor Hopkins and Kumar from the Rhinological Society recommended that oral corticosteroids should not be incorporated in the treatment of the new-onset anosmia during the COVID-19 pandemic, as they may exacerbate the severity of COVID-19 disease [10]. Nasal steroids are also not recommended for the sudden loss of smell [11]. According to the available reports, patients below 40 years of age are mostly predisposed to develop the form of COVID-19 that is only manifested by hyposmia/anosmia or taste disturbances [10,11]. Patients with sudden anosmia should be tested for SARS-Cov-2 presence and considered as potential individuals with COVID-19 [11].

The prevalence of particular COVID-19 ear, nose and throat (ENT) manifestations in various reports was presented in Table 1 [4, 7-9, 12-27]. Additional, crucial information found in these studies was also presented in Table 1.

\section{COVID-19-related crucial information for otolaryngologists/head and neck surgeons}

Otolaryngologists, especially ENT surgeons are at very high risk of SARS-Cov-2 infection as they cope with the upper respiratory tract (URT) which is the main reservoir of SARS-CoV-2. According to current recommendations of European Rhinologic Society, all non-urgent ENT surgeries should be postponed because of COVID-19 pandemic [11]. For patients requiring urgent surgery or ENT consult, otolaryngologist should wear fluid-resistant FFP3/N95 mask, disposable and fluid resistant gloves and gown, glasses or full face shield. Double-gloving during operation is recommended for surgeons [2]. A number of staff attending the OR during urgent ENT surgery should be limited to minimum [2].

Tracheostomy is one of the most frequent urgent ENT surgery. Currently, during COVID-19 pandemic, every patient requiring emergency tracheostomy should be considered as a COVID-19 positive as delaying the surgery while waiting for SARS-CoV-2 detection test may lead to patient's death [28].

For patients with intermittent dyspnea that is potentially reversible, intubation rather than tracheostomy should be performed [28]. High flow oxygen/AIRVO should not be used in these cases [28]. For individuals with constant dyspnea, in whom irreversible cause of dyspnea is strongly suspected, tracheostomy is required [28]. In patients positive for COVID-19 or in those with unknown COVID-19 status, cuffed and non-fenestrated tracheostomy tube should be used to prevent SARS-Cov-2 from aerosolizing [28]. The cuff of the endotracheal tube should not be perforated during the procedure. The mechanic ventilation should be suspended while making the opening in the trachea and during the tracheostomy tube insertion into the trachea [28]. Heat and moisture exchanger (HME) ought to be immediately connected with the tracheostomy to reduce the spread of the virus. Subsequently it should not be disconnected [28]. It is recommended to avoid humidified closed circuits to minimize the chance of the virus-induced space contamination in case of the system disjunction [28]. The closed gear used in patients after tracheostomy should be the same as used for patients connected to a mechanical ventilator [29]. After the surgery, the tracheostomy tube should not be changed until patient's COVID-19 status is positive or unknown [28]. Suction other than closed in line suction must be avoided while performing respiratory tract toilet [28].

Flexible laryngoscopy is another aerosol-generating procedure that exposes otolaryngologists to COVID-19 infection [29]. It should be performed only if absolutely necessary.

It is recommended that every patient with unknown status of COVID-19 should be examined by otolaryngologist that is fully equipped [29]. It is of great importance as the mean incubation time reaches 5.2 days, with $95 \%$ of the distribution at 12.5 days [5]. The minimal personal protective equipment (PPE) includes FF3/N95 mask, gloves, gown, eye protection and a cap [29]. If possible, patients not requiring urgent ENT consult, especially those treated for chronic ENT diseases, should be consulted by phone. Individuals requiring ENT visit are obligated to have their body temperature measured before entering the outpatient clinic [29]. Additionally, their recent travel status should be assessed as the patients could be asymptomatic during the first several days after SARS-CoV-2 infection [29].

Currently, there is no evidence against topical corticosteroids use in patients with chronic nasal corticosteroids use for rhinosinusitis or allergic rhinitis [11].

\section{COVID-19 diagnosis}

Symptoms including fever, unproductive cough and dyspnea in combination with a history of travel to areas with confirmed COVID-19 cases strongly suggest COVID-19 disease [30]. Currently, patients with severe lower respiratory tract infection should be considered as potential SARS-CoV-2 carriers [30]. Nevertheless, to confirm the diagnosis of COVID-19 molecular test must detect SARS-CoV-2 presence [30]. The specific test for SARS-CoV-2 detection is the real-time reverse transcriptase-polymerase chain reaction (RT-PCR) test. Presently, it is the recommended test to diagnose SARS-Cov-2 infection. A positive RT-PCT test for SARS-CoV-2 confirms the diagnosis of COVID-19 in the vast majority of cases, nevertheless, false-positive results can also occur [30]. RT-PCR is considered as highly specific, however, in a number of cases its sensitivity seemed not to be enough to diagnose the disease. RT-PCR sensitivity range 


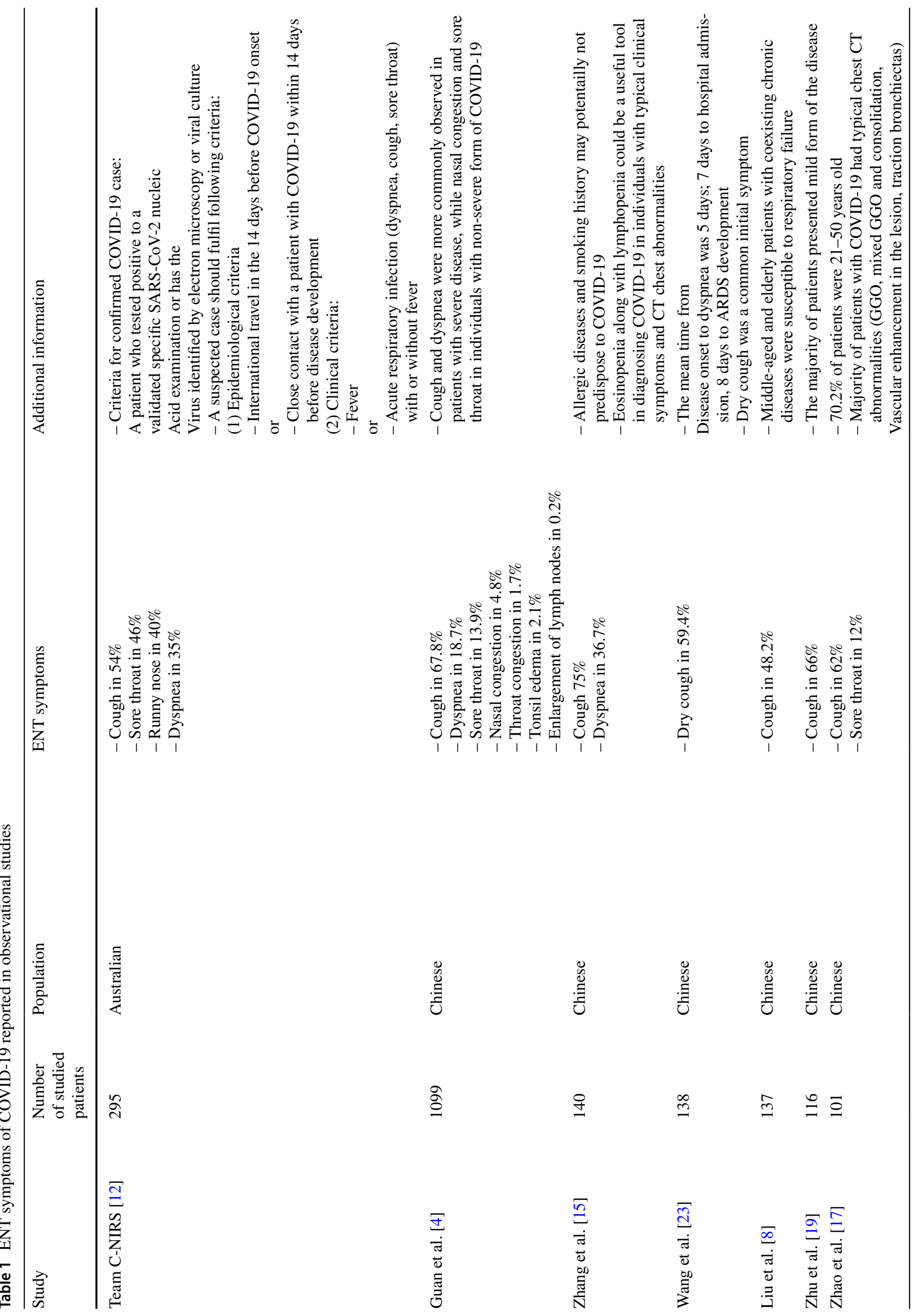




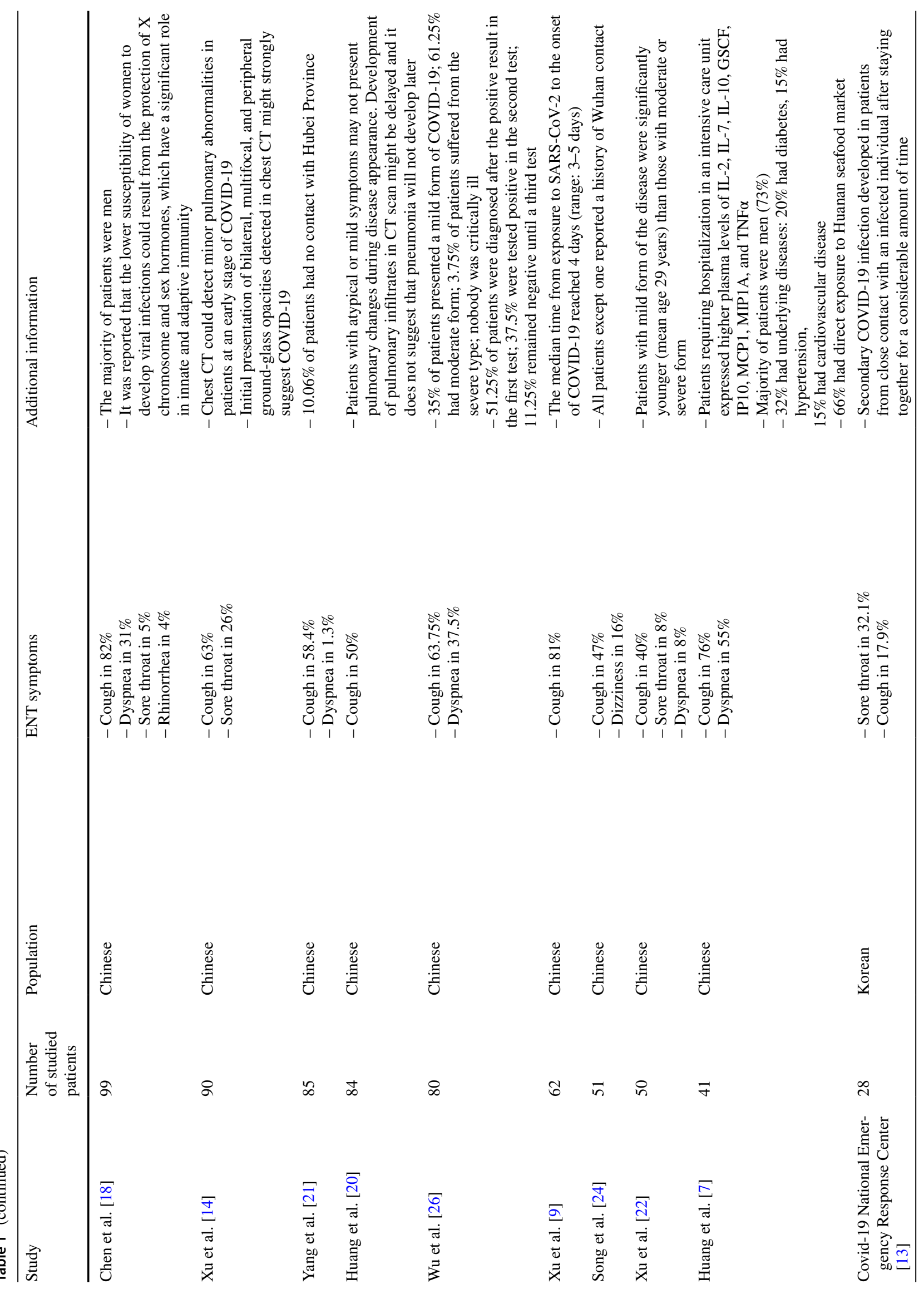


differed between reports from various counties. It could be as low as $60-70 \%$ [31] or as high as $97 \%$ [32]. Keeping in mind such detection discrepancies, doctors should repeat the test after several days.

Molecular examination is performed on specimens obtained mainly from the respiratory tract and sometimes from stool [30]. In severe form of the disease, blood is tested for SARS-CoV-2 presence [30]. Nasopharyngeal swabs, oropharyngeal swabs, bronchoalveolar lavage, endotracheal aspirates or sputum could be taken for testing [30].

Nasopharyngeal swabs are most commonly taken for SARS-CoV-2 examination.

Nasopharyngeal and oropharyngeal swabs are currently recommended for detecting SARS-CoV-2 and diagnosing COVID-19, nevertheless obtaining specimens from this sites may be harmful and may lead to bleeding that is especially important in cases where recurrent analysis is required [33]. Additionally, it was also reported that swabs taken from URT, especially from nasopharynx or oropharynx might not be enough sensitive to detect SARS-CoV-2 [34].

According to current recommendations, two negative tests conducted in at least 24-h interval could exclude COVID19. Nevertheless, Wu et al. presented a case of COVID19 with double negative SARS-CoV-2 tests obtained from nasopharyngeal swabs [35]. The authors suggested that in patients with clinical symptoms strongly suggesting COVID19 disease, sputum or bronchoalveolar lavage fluid (BALF) should be taken for examination [35]. The patient presented in this case was co-infected by influenza A virus that was detected in the nasopharyngeal swab. Simultaneously, the patient was negative for SARS-CoV-2 [35]. This report highlights the possibility of false-negative results for samples obtained from URT while diagnosing COVID-19 [35].

Sputum could be analyzed for SARS-CoV-19 presence however it may be difficult to obtain in non-productive patients [33]. It was speculated that saliva may serve as a potential, non-invasive material for diagnosing COVID-19 [33]. Saliva could be self-collected by a patient by spitting into a sterile container. That could eliminate the exposure of healthcare service to close contact with a patient while taking naso- or oropharyngeal swabs [33]. It was also reported that in several cases saliva was more accurate material to detect coronavirus than nasopharyngeal swab [34]. Authors from China reported that SARS-CoV-2 was detected in saliva specimens obtained from $91.7 \%$ of patients with COVID-19 [33]. Saliva was taken into a sterile container from patients while spitting saliva from throat and subsequently analyzed using nucleic acid extraction and RT-PCR test [33].

According to studies, computed tomography (CT) of the chest seemed to be very useful in diagnosing COVID-19. It was suggested that chest CT could be even more sensitive in detecting COVID-19 than repeated RT-PCR test. Ai et al. 
conducted a large cohort study performed on patients with positive RT-PCR test revealing that the sensitivity of chest CT in implying the presence of COVID-19 reached 97\% [32]. The sensitivity of RT-PCR tests and chest CT for diagnosing COVID-19 in suspected individuals reached 59\% and $88 \%$, respectively [32]. $60 \%$ to $93 \%$ of patients in this cohort presented initial positive chest CT suggesting COVID-19 before the initial RT-PCR test detected SARS-CoV-2 [32]. $42 \%$ of patients with COVID-19 presented improvement in the follow-up chest CT before the test based on RT-PCR results turned negative [32]. The authors suggested that chest CT could be considered as a sensitive and useful test in detecting COVID-19 in the areas affected by COVID-19 epidemic [32]. CT of the thoracic cavity revealing groundglass opacities, infiltrates and bronchovascular thickening consolidations strongly suggest SARS-CoV-2 infection [23].

According to previous reports, we speculate that during COVID-19 pandemic, chest CT should be performed in patients before ENT operations. It could be of great value in individuals with negative RT-PCR.

There are currently no laboratory abnormalities specific for COVID-19 diagnosis. According to various authors, complete blood count usually revealed the normal or decreased level of white blood cells and thrombocytes, and reduced number of lymphocytes [30]. The levels of erythrocyte sedimentation rate and C-reactive protein were mainly increased, while procalcitonin remained normal in the majority of cases [30]. Increased levels of D-dimer, serum creatinine, creatinine phosphokinase, lactate dehydrogenase, prothrombin time, and aminotransferases namely alanine transaminase and aspartate transaminase, usually indicated severe form of COVID-19 [30]. High D-dimer concentration and significant lymphopenia were correlated with higher mortality [30]. Patients with ENT manifestations of COVID-19 may present similar laboratory abnormalities to individuals in alike disease stage but with other COVID-19 symptoms.

It was implied that the loop-mediated isothermal amplification (LAMP) assay could be a potentially useful tool in diagnosing COVID-19 because of its diagnostic sensitivity exceeding $95 \%$ [36]. LAMP reaction is a novel nucleic acid amplification analysis that amplifies DNA [36]. It is characterized by very specific, efficient and quick test [36]. LAMP technology is believed to be of higher stability and sensitivity than PCR [36].

High levels of interleukin-1B (IL-1B), interferon- $\gamma$ (IFN- $\gamma$ ), interferon gamma-induced protein 10 (IP10), and monocyte chemoattractant protein 1 (MCP1) were found in patients with COVID-19. T-helper-1 (Th1) cell response was potentially dominant in infected individuals [7]. Nevertheless, the levels of IL-4 and IL-10 that are related to T-helper-2 (Th2) cell response, were also elevated [7]. Additionally, patients with severe form of the disease, requiring hospitalization in the intensive care unit (ICU), expressed high levels of granulocyte-colony stimulating factor (GCSF), IP10, MCP1, macrophage Inflammatory protein 1alpha (MIP1A), and tumor necrosis factor alpha (TNF $\alpha$ ) [7]. Concentrations of these molecules were significantly higher than in patients with less severe disease [7]. The authors speculated that these molecules may potentially reflect a severe form of COVID-19 [7].

\section{Vaccine}

Vaccine against SARS-CoV-2 is not available yet. The most promising target in developing a vaccine against SARSCoV-2 seems to be the viral spike protein (S protein) [37]. The first vaccine is examined in the clinical trial (Phase 1) in human beings in the United States [37]. It uses a messenger RNA platform to achieve $S$ protein expression to stimulate an immune response [37].

\section{Therapy for COVID-19 (Fig. 1)}

Previously known SARS-CoV, and novel SARS-CoV-2 express genomic similarity (approximately $82 \%$ similarity), thus therapeutic option used for SARS-CoV could potentially be useful in treating SARS-CoV-2 infection [1, 36]. Partial genomic similarity was also observed between SARS-CoV-2 and Middle East Respiratory Syndrome coronavirus (MERS-CoV).

No therapeutic agent has already been proven to be efficient in SARS-Cov-2 infection treatment. No drug is currently approved for COVD-19. However, several agents are currently investigated in clinical trials [1].

\section{Agents being investigated in COVID-19}

There are currently several agents used in COVID-19 therapy. Randomized controlled studies analyzing their potential positive effects in COVID-19 management are lacking. Reports on these agents' use in COVID-19 are mainly based on in vitro or extrapolated evidence. Clinical usefulness of these drugs appeared in case reports.

\section{Lopinavir (LPV)-Ritonavir (RTV)}

Therapy based on combined LPV and RTV, protease inhibitors recommended for HIV-1 treatment, showed antiviral activity against SARS-CoV in in vitro study [38]. Promising effects were also found in managing MERS-CoV with LPVRTV in a study on animals [39].

The efficiency of LPV-RTV use for COVID-19 treatment has not already been established. Further clinical studies are required to assess the potential benefits of these agents in COVID-19. 
Fig. 1 Potential therapeutic options for COVID-19

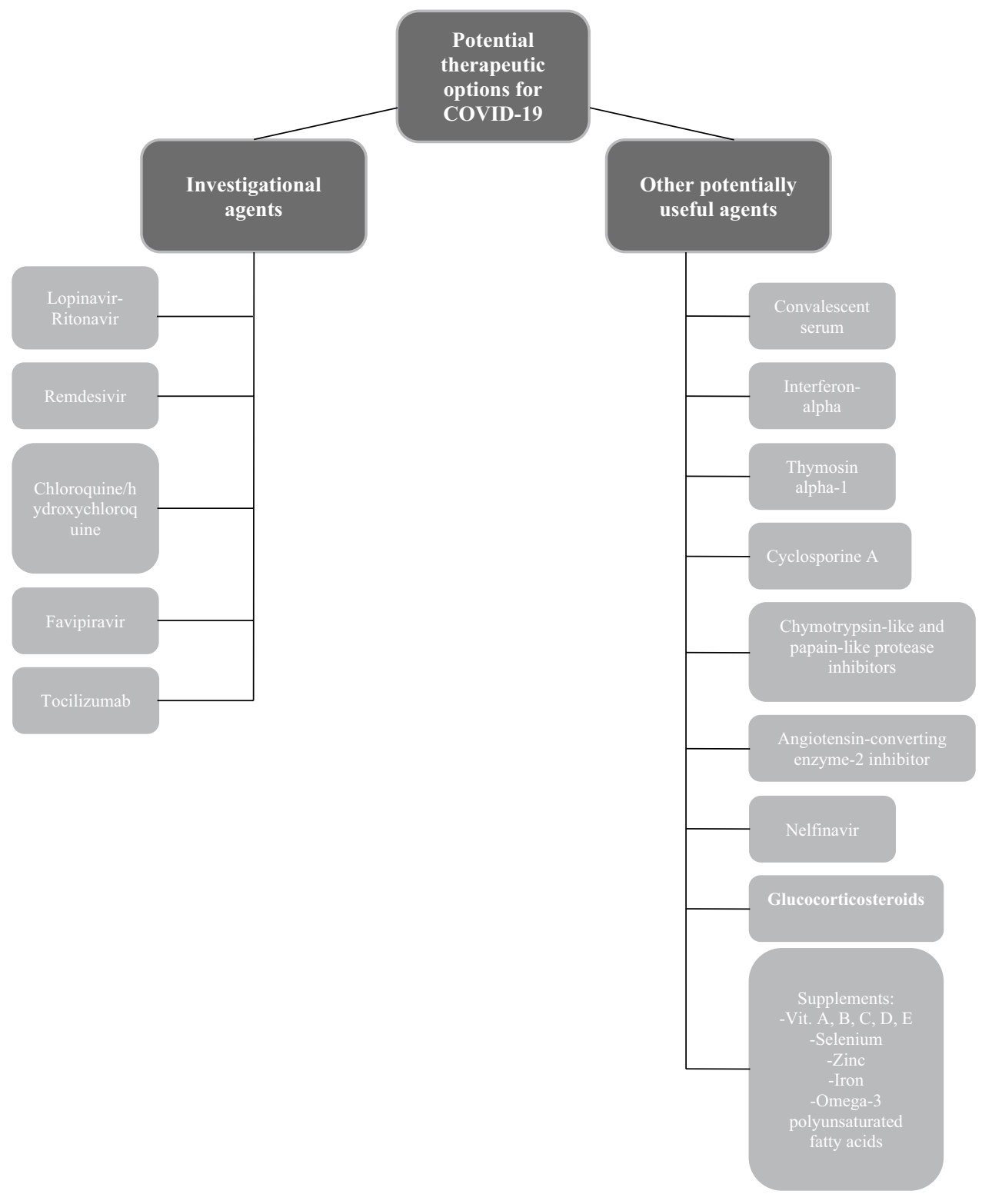

Cao et al. conducted a study on 199 patients with COVID-19 [40]. The authors reported that LPV-RTV therapy was not effective in adults with severe COVID-19. The use of LPV-PTV (dosage 400 and $100 \mathrm{mg}$, respectively) two times a day for two weeks showed no significant difference in the time to clinical improvement, duration of the stay in ICU, duration of mechanical ventilation, duration of oxygen support, or in mortality rate from patients undergoing standard care without LPV-RTV under the observation for 28 days [40].

Deng et al. found that therapy based on LPV-RTV in combination with Arbidol, a drug used against influenza virus, was more efficient than LPV-RTV use only in confirmed COVID-19 cases [41].

\section{Remdesivir}

Remdesivir, a novel nucleotide analogue could be a potential therapeutic option for COVID-19 [42]. It appeared to have activity against SARS-CoV-2 in in vitro study [42]. Remdesivir was clinically used for the first time in 35-years old American with COVID-19 when the patient's clinical status started to exacerbate [43]. Currently, there are two ongoing large cohort clinical trials designed to analyze the efficiency and safety of remdesivir in patients with mild, moderate, and severe COVID-19 [44]. Preliminary results of these studies have not been reported yet. 


\section{Chloroquine/hydroxychloroquine}

Chloroquine/hydroxychloroquine expressed promising results in COVID-19 treatment in various studies [45, 46]. Chloroquine and hydroxychloroquine presented antiviral activity against SARS-CoV-2 in in vitro and in vivo studies [46, 47]. Stronger antiviral function was observed for hydroxychloroquine than for chloroquine [46]. Chloroquine was able to decrease the length of hospitalization and to improve COVID-19 pneumonia therapy. It expressed positive results with potential safety in fighting COVID-19-associated pneumonia in the Chinese multicenter clinical trials [48]. In a study conducted by Gautret et al., $100 \%$ of individuals with COVID-19 undergoing therapy based on hydroxychloroquine and azithromycin were healed, while only $57.1 \%$ of patients on hydroxychloroquine alone and only $12.5 \%$ of individuals from control group improved after the therapy [45]. Chloroquine is currently recommended to be incorporated in the upcoming version of the "Guidelines for the Prevention, Diagnosis, and Treatment of Pneumonia Caused by COVID-19" issued by the National Health Commission of the People's Republic of China [48].

\section{Favipiravir}

Favipiravir is a novel RNA-dependent RNA polymerase inhibitor [49]. It was approved for novel influenza virus in China [49]. Favipiravir expresses its inhibiting activity against viral RNA polymerase after initially being transformed to an active phosphoribosylated form (favipiravirRTP) in cells, where it is identified as a substrate by the viral RNA polymerase [49]. It could potentially be useful in COVID-19 treatment as SARS-CoV-2 is a RNA virus [49]. Encouraging results were already achieved by a clinical trial conducted in the Clinical Medical Research Center of the National Infectious Diseases and the Third People's Hospital of Shenzhen [49]. Authors of this trial reported that favipiravir expressed stronger antiviral activity than LPV-RTV with significantly less adverse effects [49].

\section{Tocilizumab}

Tocilizumab is a recombinant humanized monoclonal antibody against the interleukin- 6 .

(IL-6) receptor [44]. It showed promising results in treating severely or critically ill individuals with COVID19 with coexisting massive changes in lungs and significantly elevated levels of IL-6 [44].

\section{Other potentially useful agents in COVID-19}

\section{Convalescent serum}

Sera obtained from convalescent patients could potentially be used in COVID-19 therapy in subjects with early symptoms [50]. It could prevent COVID-19 development in exposed individuals [50].

\section{Interferon-alpha (INF-alpha)}

Zhang et al. reported the potential therapeutic effect of INF-alpha and combined INF-alpha-2a with ribavirin in patients with SARS and severe MERS-CoV, respectively [47].

\section{Thymosin alpha-1}

Thymosin alpha- 1 express the ability to elevate the resistance to glucocorticosteroids-induced death of thymocytes. It was observed that thymosin alpha- 1 acted as an immune booster in patients with SARS and was able to restrain the spread of the infection [47]. In patients with COVID-19 in whom incorporating glucocorticosteroids is planned, thymosin alpha-1 should be considered before glucocorticosteroid use to prevent glucocorticosteroid-induced death of thymocytes [47].

\section{Cyclosporine A}

It was speculated that non-immunosuppressive derivatives of cyclosporine A might act as COVID-19 inhibitors [47].

\section{Chymotrypsin-like (3C-like) and papain-like protease (PLP) inhibitors}

Therapy targeting coronavirus proteases, namely chymotrypsin-like (3C-like) and papain-like protease (PLP) could potentially be useful in COVID-19 treatment [47]. 3C-like protease was observed to be encoded in COVID-19 [47]. Cinanserin express the ability to suppress 3C-like protease subsequently implying its potential usefulness in facing COVID-19 [47]. Cinanserin was able to suppress SARS$\mathrm{CoV}$ replication [47]. Flavonoids presented the inhibitory effects against MERS-CoV and SARS-CoV chymotrypsinlike proteases [47]. Diarylheptanoid, a PLP inhibitor, expressed the ability to inhibit SARS-CoV PLP [47]. Targeting coronavirus proteases could potentially be useful in facing COVID-19 [47]. 


\section{Angiotensin-converting enzyme-2 (ACE2) inhibitors}

ACE2 was found to be a critical receptor of SARS-CoV-2 invasion [1]. SARS-CoV-2 Spike (S) glycoprotein binding with host ACE2 enables the virus to invade the human organism [1]. Suppressing SARS-CoV-2 S glycoprotein from linking with ACE2 could be a promising therapeutic option for SARS-CoV-2 infection development [1].

Recombinant human monoclonal antibody scFv80R against S1 domain of the SARS-CoV was found [47]. It was reported that this antibody was able to suppress SARS-CoV S glycoprotein from binding to ACE2 and counteract SARSCoV [47].

Emodin expressed antiviral activity [47]. It suppressed SARS-CoV and ACE2 fusion because of its ability to compete with SARS-CoV S glycoprotein [47]. This observation implied the potential usefulness of emodin in COVID-19 therapy [47]. Similar competition with SARS-CoV S glycoprotein for connection to the ACE2 receptor was also observed for promazine [47].

\section{Nelfinavir}

Nelfinavir, a HIV protease inhibitor, was able to inhibit SARS-CoV, thus it could be also considered as a potential therapeutic option for SARS-CoV-2 [47].

\section{Glucocorticosteroids}

World Health Organization (WHO) and the Centers for Disease Control and Prevention (CDC) recommended that glucocorticosteroids should not be commonly administered in individuals with COVID-19 for managing SARS-CoV2-induced pneumonia or acute respiratory distress syndrome (ARDS) unless required for another reason, like worsening of the chronic obstructive pulmonary disease, asthma or septic shock [44]. Nevertheless, it was reported that in patients with COVID-19 pneumonia who progressed to ARDS, methylprednisolone brought favorable results [44].

\section{Supplements}

It was speculated that Vitamin A, B, C, D, E, omega-3 polyunsaturated fatty acids, selenium, zinc and iron supplementation could be beneficial in COVID-19 management [47].

\section{Conclusion}

Otorhinolaryngological manifestations are not rare symptoms of COVID-19, especially in mild or moderate form of the disease. The most common ENT dysfunctions observed in patients infected with SARS-CoV-2 are cough, mainly dry, sore throat and dyspnea. Rhinorrhea, nasal congestion and dizziness may also be present. COVID-19 could also manifest as a sudden hyposmia or anosmia not accompanied by any other symptom. Whether SARS-CoV-2-induced hyposmia/anosmia is reversible remain unknown. URT symptoms are commonly observed in younger patients and usually appear initially. They may precede the development of severe COVID-19. Mild cases of COVID-19 without clinical pneumonia could represent the clinical presentation of the disease in young, healthy individuals. ENT symptoms may be present before the patient tested positive for SARSCoV-2 in molecular analysis.

Otolaryngologist is of great risk of becoming infected with SARS-CoV as they cope with URT during performing a consult, clinical examination, sample taking and a surgery. ENT specialist is one of the specialists that patients with COVID-19 contact most commonly. During COVID19 pandemic, every patient with cough, sore throat, dyspnea, hyposmia/anosmia and a history of travel to the region with confirmed COVID-19 cases, should be considered as a potential COVID-19 case. Otolaryngologist should wear fluid-resistant FFP3/N95 mask, disposable and fluid resistant gloves and gown, glasses or a full face shield when examining such individual. According to previous reports, we speculate that during COVID-19 pandemic, chest CT should be performed in patients before ENT operations. It could be of great value in individuals with negative RT-PCR.

Additional studies analyzing why not all patients develop ENT symptoms during SARS-CoV-2 infection are needed. Further research is needed to determine the mechanism leading to loss of smell.

Author contributions JK: Substantial contribution to the design of the manuscript, literature search, data analysis and interpretation. Preparing the main paper. WK: Substantial contribution to literature search, data analysis and interpretation. KZ: Substantial contribution to literature search. TZ: Drafting the manuscript and revising it critically for important intellectual content. Final approval of the manuscript. All authors read and approved the final manuscript. All listed authors have approved the manuscript before submission, including the names and order of authors.

Funding Not applicable.

\section{Compliance with ethical standards}

All the research included in this manuscript meet the ethical guidelines, including adherence to the legal requirements of the study country. The study protocol complied with the 1964 Helsinki declaration and its later amendments. I confirm that the manuscript has not been published or submitted for publication to any other journal.

Conflicts of interests The authors declare that they have no conflicts of interests. 
Informed consent Not applicable.

Open Access This article is licensed under a Creative Commons Attribution 4.0 International License, which permits use, sharing, adaptation, distribution and reproduction in any medium or format, as long as you give appropriate credit to the original author(s) and the source, provide a link to the Creative Commons licence, and indicate if changes were made. The images or other third party material in this article are included in the article's Creative Commons licence, unless indicated otherwise in a credit line to the material. If material is not included in the article's Creative Commons licence and your intended use is not permitted by statutory regulation or exceeds the permitted use, you will need to obtain permission directly from the copyright holder. To view a copy of this licence, visit http://creativecommons.org/licenses/by/4.0/.

\section{References}

1. Guo YR, Cao QD, Hong ZS, Tan YY, Chen SD, Jin HJ, Tan KS, Wang DY, Yan Y (2020) The origin, transmission and clinical therapies on coronavirus disease 2019 (COVID-19) outbreak-an update on the status. Mil Med Res 7(1):11. https:// doi.org/10.1186/s40779-020-00240-0

2. GOV.UK (2020) COVID-19: infection prevention and control. https://www.gov.uk/government/publications/wuhan-novel -coronavirus-infection-prevention-and-control. Accessed 27 March 2020

3. van Doremalen N, Bushmaker T, Morris DH, Holbrook MG, Gamble A, Williamson BN, Tamin A, Harcourt JL, Thornburg NJ, Gerber SI, Lloyd-Smith JO, de Wit E, Munster VJ (2020) Aerosol and Surface Stability of SARS-CoV-2 as Compared with SARS-CoV-1. N Engl J Med. https://doi.org/10.1056/ NEJMc2004973

4. Guan WJ, Ni ZY, Hu Y, Liang WH, Ou CQ, He JX, Liu L, Shan H, Lei CL, Hui DSC, Du B, Li LJ, Zeng G, Yuen KY, Chen RC, Tang CL, Wang T, Chen PY, Xiang J, Li SY, Wang JL, Liang ZJ, Peng YX, Wei L, Liu Y, Hu YH, Peng P, Wang JM, Liu JY, Chen Z, Li G, Zheng ZJ, Qiu SQ, Luo J, Ye CJ, Zhu SY, Zhong NS, China Medical Treatment Expert Group for C (2020) Clinical Characteristics of Coronavirus Disease 2019 in China. N Engl J Med. https://doi.org/10.1056/NEJMoa2002032

5. Li Q, Guan X, Wu P, Wang X, Zhou L, Tong Y, Ren R, Leung KSM, Lau EHY, Wong JY, Xing X, Xiang N, Wu Y, Li C, Chen Q, Li D, Liu T, Zhao J, Li M, Tu W, Chen C, Jin L, Yang R, Wang Q, Zhou S, Wang R, Liu H, Luo Y, Liu Y, Shao G, Li H, Tao Z, Yang Y, Deng Z, Liu B, Ma Z, Zhang Y, Shi G, Lam TTY, Wu JTK, Gao GF, Cowling BJ, Yang B, Leung GM, Feng Z (2020) Early Transmission dynamics in Wuhan, China, of novel coronavirus-infected pneumonia. N Engl J Med. https:// doi.org/10.1056/NEJMoa2001316

6. Zhou F, Yu T, Du R, Fan G, Liu Y, Liu Z, Xiang J, Wang Y, Song B, Gu X, Guan L, Wei Y, Li H, Wu X, Xu J, Tu S, Zhang Y, Chen H, Cao B (2020) Clinical course and risk factors for mortality of adult inpatients with COVID-19 in Wuhan, China: a retrospective cohort study. Lancet. https://doi.org/10.1016/ S0140-6736(20)30566-3

7. Huang C, Wang Y, Li X, Ren L, Zhao J, Hu Y, Zhang L, Fan G, Xu J, Gu X, Cheng Z, Yu T, Xia J, Wei Y, Wu W, Xie X, Yin W, Li H, Liu M, Xiao Y, Gao H, Guo L, Xie J, Wang G, Jiang R, Gao Z, Jin Q, Wang J, Cao B (2020) Clinical features of patients infected with 2019 novel coronavirus in Wuhan, China. Lancet 395(10223):497-506. https://doi.org/10.1016/ S0140-6736(20)30183-5
8. Liu K, Fang YY, Deng Y, Liu W, Wang MF, Ma JP, Xiao W, Wang YN, Zhong MH, Li CH, Li GC, Liu HG (2020) Clinical characteristics of novel coronavirus cases in tertiary hospitals in Hubei Province. Chin Med J (Engl). https://doi.org/10.1097/ CM9.0000000000000744

9. Xu XW, Wu XX, Jiang XG, Xu KJ, Ying LJ, Ma CL, Li SB, Wang HY, Zhang S, Gao HN, Sheng JF, Cai HL, Qiu YQ, Li LJ (2020) Clinical findings in a group of patients infected with the 2019 novel coronavirus (SARS-Cov-2) outside of Wuhan, China: retrospective case series. BMJ 368:m606. https://doi. org/10.1136/bmj.m606

10. Hopkins C, Kumar N (2020) Loss of sense of smell as marker of COVID-19 infection (letter). ENT UK website. https://www. entuk.org/sites/default/files/files/Loss\%20of\%20sense $\% 20$ of $\% 20$ smell $\% 20$ as $\% 20$ marker\%20of\%20COVID.pdf Accessed 21 March 2020

11. European Rhinologic Society (2020). https://www.europeanrh inologicsociety.org/ Accessed March 2020

12. Team C-NIRS (2020) COVID-19, Australia: Epidemiology Report 7 (Reporting week ending 19:00 AEDT 14 March 2020). Commun Dis Intell 2018:44. https://doi.org/10.33321/cdi.2020.44.23

13. Covid-19 National Emergency Response Center E, Case Management Team KCfDC, Prevention (2020) Early epidemiological and clinical characteristics of 28 cases of coronavirus disease in South Korea. Osong Public Health Res Perspect 11(1):8-14. https://doi. org/10.24171/j.phrp.2020.11.1.03

14. Xu X, Yu C, Qu J, Zhang L, Jiang S, Huang D, Chen B, Zhang Z, Guan W, Ling Z, Jiang R, Hu T, Ding Y, Lin L, Gan Q, Luo L, Tang X, Liu J (2020) Imaging and clinical features of patients with 2019 novel coronavirus SARS-CoV-2. Eur J Nucl Med Mol Imaging. https://doi.org/10.1007/s00259-020-04735-9

15. Zhang JJ, Dong X, Cao YY, Yuan YD, Yang YB, Yan YQ, Akdis CA, Gao YD (2020) Clinical characteristics of 140 patients infected with SARS-CoV-2 in Wuhan, China. Allergy. https:// doi.org/10.1111/all.14238

16. Han W, Quan B, Guo Y, Zhang J, Lu Y, Feng G, Wu Q, Fang F, Cheng L, Jiao N, Li X, Chen Q (2020) The course of clinical diagnosis and treatment of a case infected with coronavirus disease 2019. J Med Virol. https://doi.org/10.1002/jmv.25711

17. Zhao W, Zhong Z, Xie X, Yu Q, Liu J (2020) Relation between chest $\mathrm{CT}$ findings and clinical conditions of coronavirus disease (COVID-19) pneumonia: a multicenter study. AJR Am J Roentgenol. https://doi.org/10.2214/AJR.20.22976

18. Chen N, Zhou M, Dong X, Qu J, Gong F, Han Y, Qiu Y, Wang J, Liu Y, Wei Y, Xia J, Yu T, Zhang X, Zhang L (2020) Epidemiological and clinical characteristics of 99 cases of 2019 novel coronavirus pneumonia in Wuhan, China: a descriptive study. Lancet 395(10223):507-513. https://doi.org/10.1016/S0140 $-6736(20) 30211-7$

19. Zhu W, Xie K, Lu H, Xu L, Zhou S, Fang S (2020) Initial clinical features of suspected Coronavirus Disease 2019 in two emergency departments outside of Hubei, China. J Med Virol. https://doi. org/10.1002/jmv.25763

20. Huang Y, Tu M, Wang S, Chen S, Zhou W, Chen D, Zhou L, Wang M, Zhao Y, Zeng W, Huang Q, Xu H, Liu Z, Guo L (2020) Clinical characteristics of laboratory confirmed positive cases of SARS-CoV-2 infection in Wuhan, China: A retrospective single center analysis. Travel Med Infect Dis. https://doi.org/10.1016/j. tmaid.2020.101606

21. Yang W, Cao Q, Qin L, Wang X, Cheng Z, Pan A, Dai J, Sun Q, Zhao F, Qu J, Yan F (2020) Clinical characteristics and imaging manifestations of the 2019 novel coronavirus disease (COVID19): A multi-center study in Wenzhou city, Zhejiang, China. J Infect. https://doi.org/10.1016/j.jinf.2020.02.016

22. Xu YH, Dong JH, An WM, Lv XY, Yin XP, Zhang JZ, Dong L, Ma X, Zhang HJ, Gao BL (2020) Clinical and computed 
tomographic imaging features of novel coronavirus pneumonia caused by SARS-CoV-2. J Infect. https://doi.org/10.1016/j. jinf.2020.02.017

23. Wang D, Hu B, Hu C, Zhu F, Liu X, Zhang J, Wang B, Xiang H, Cheng Z, Xiong Y, Zhao Y, Li Y, Wang X, Peng Z (2020) Clinical characteristics of 138 hospitalized patients with 2019 novel coronavirus-infected pneumonia in Wuhan, China. Jama. https:// doi.org/10.1001/jama.2020.1585

24. Song F, Shi N, Shan F, Zhang Z, Shen J, Lu H, Ling Y, Jiang Y, Shi Y (2020) Emerging 2019 novel coronavirus (2019-nCoV) pneumonia. Radiology 295(1):210-217. https://doi.org/10.1148/ radiol.2020200274

25. Chang LM, Wei L, Xie L, Zhu G, Dela Cruz CS, Sharma L (2020) Epidemiologic and clinical characteristics of novel coronavirus infections involving 13 patients outside Wuhan, China. Jama. https ://doi.org/10.1001/jama.2020.1623

26. Wu J, Liu J, Zhao X, Liu C, Wang W, Wang D, Xu W, Zhang C, Yu J, Jiang B, Cao H, Li L (2020) Clinical characteristics of imported cases of COVID-19 in Jiangsu Province: a multicenter descriptive study. Clin Infect Dis. https://doi.org/10.1093/cid/ ciaa199

27. Spiteri G, Fielding J, Diercke M, Campese C, Enouf V, Gaymard A, Bella A, Sognamiglio P, Sierra Moros MJ, Riutort AN, Demina YV, Mahieu R, Broas M, Bengner M, Buda S, Schilling J, Filleul L, Lepoutre A, Saura C, Mailles A, Levy-Bruhl D, Coignard B, Bernard-Stoecklin S, Behillil S, van der Werf S, Valette M, Lina B, Riccardo F, Nicastri E, Casas I, Larrauri A, Salom Castell M, Pozo F, Maksyutov RA, Martin C, Van Ranst M, Bossuyt N, Siira L, Sane J, Tegmark-Wisell K, Palmerus M, Broberg EK, Beaute J, Jorgensen P, Bundle N, Pereyaslov D, Adlhoch C, Pukkila J, Pebody R, Olsen S, Ciancio BC (2020) First cases of coronavirus disease 2019 (COVID-19) in the WHO European Region, 24 January to 21 February 2020. Euro Surveill. https:// doi.org/10.2807/1560-7917.ES.2020.25.9.2000178

28. Harrison L Ramsden J, Winter S (2020) Guidance for Surgical Tracheostomy and Tracheostomy Tube Change during the COVID-19 Pandemic. https://www.entuk.org/tracheostomy-guida nce-during-covid-19-pandemic. Accessed 19 March 2020

29. Chan JYK, Wong EWY, Lam W (2020) Practical aspects of otolaryngologic clinical services during the 2019 novel coronavirus epidemic: an experience in Hong Kong. JAMA Otolaryngol Head Neck Surgery. https://doi.org/10.1001/jamaoto.2020.0488

30. Singhal T (2020) A review of coronavirus disease-2019 (COVID19). Indian J Pediatr 87(4):281-286. https://doi.org/10.1007/s1209 8-020-03263-6

31. Kanne JP, Little BP, Chung JH, Elicker BM, Ketai LH (2020) Essentials for Radiologists on COVID-19: An update-radiology scientific expert panel. Radiology. https://doi.org/10.1148/radio 1.2020200527

32. Ai T, Yang Z, Hou H, Zhan C, Chen C, Lv W, Tao Q, Sun Z, Xia L (2020) Correlation of chest CT and RT-PCR testing in coronavirus disease (COVID-19) in China: a report of 1014 Cases. Radiology. https://doi.org/10.1148/radiol.2020200642

33. To KK, Tsang OT, Chik-Yan Yip C, Chan KH, Wu TC, Chan JMC, Leung WS, Chik TS, Choi CY, Kandamby DH, Lung DC, Tam AR, Poon RW, Fung AY, Hung IF, Cheng VC, Chan JF, Yuen KY (2020) Consistent detection of 2019 novel coronavirus in saliva. Clin Infect Dis. https://doi.org/10.1093/cid/ciaa149

34. To KK, Lu L, Yip CC, Poon RW, Fung AM, Cheng A, Lui DH, Ho DT, Hung IF, Chan KH, Yuen KY (2017) Additional molecular testing of saliva specimens improves the detection of respiratory viruses. Emerg Microbes Infect 6(6):e49. https://doi.org/10.1038/ emi.2017.35

35. Wu X, Cai Y, Huang X, Yu X, Zhao L, Wang F, Li Q, Gu S, Xu T, Li Y, Lu B, Zhan Q (2020) Co-infection with SARS-CoV-2 and influenza a virus in patient with pneumonia, China. Emerg Infect Dis. https://doi.org/10.3201/eid2606.200299s

36. Nguyen T, Duong Bang D, Wolff A (2020) 2019 Novel coronavirus disease (COVID-19): paving the road for rapid detection and point-of-care diagnostics. Micromachines (Basel). https://doi. org/10.3390/mi11030306

37. ClinicalTrials.org (2020) Safety and immunogenicity study of 2019-nCoV vaccine (mRNA-1273) to prevent SARS-CoV-2 infection. https://clinicaltrials.gov/ct2/show/NCT04283461. Accessed 19 March 2020

38. Groneberg DA, Poutanen SM, Low DE, Lode H, Welte T, Zabel $P(2005)$ Treatment and vaccines for severe acute respiratory syndrome. Lancet Infect Dis 5(3):147-155. https://doi.org/10.1016/ S1473-3099(05)01307-1

39. Chan JF, Yao Y, Yeung ML, Deng W, Bao L, Jia L, Li F, Xiao C, Gao H, Yu P, Cai JP, Chu H, Zhou J, Chen H, Qin C, Yuen KY (2015) Treatment With Lopinavir/Ritonavir or Interferon-beta1b improves outcome of MERS-CoV infection in a nonhuman primate model of common marmoset. J Infect Dis 212(12):19041913. https://doi.org/10.1093/infdis/jiv392

40. Cao B, Wang Y, Wen D, Liu W, Wang J, Fan G, Ruan L, Song B, Cai Y, Wei M, Li X, Xia J, Chen N, Xiang J, Yu T, Bai T, Xie X, Zhang L, Li C, Yuan Y, Chen H, Li H, Huang H, Tu S, Gong F, Liu Y, Wei Y, Dong C, Zhou F, Gu X, Xu J, Liu Z, Zhang Y, Li H, Shang L, Wang K, Li K, Zhou X, Dong X, Qu Z, Lu S, Hu X, Ruan S, Luo S, Wu J, Peng L, Cheng F, Pan L, Zou J, Jia C, Wang J, Liu X, Wang S, Wu X, Ge Q, He J, Zhan H, Qiu F, Guo L, Huang C, Jaki T, Hayden FG, Horby PW, Zhang D, Wang C (2020) A trial of lopinavir-ritonavir in adults hospitalized with severe Covid-19. N Engl J Med. https://doi.org/10.1056/NEJMo a2001282

41. Deng L, Li C, Zeng Q, Liu X, Li X, Zhang H, Hong Z, Xia J (2020) Arbidol combined with LPV/r versus LPV/r alone against corona virus disease 2019: a retrospective cohort study. J Infect. https://doi.org/10.1016/j.jinf.2020.03.002

42. Wang M, Cao R, Zhang L, Yang X, Liu J, Xu M, Shi Z, Hu Z, Zhong W, Xiao G (2020) Remdesivir and chloroquine effectively inhibit the recently emerged novel coronavirus $(2019-n \mathrm{CoV})$ in vitro. Cell Res 30(3):269-271. https://doi.org/10.1038/s4142 2-020-0282-0

43. Holshue ML, DeBolt C, Lindquist S, Lofy KH, Wiesman J, Bruce H, Spitters C, Ericson K, Wilkerson S, Tural A, Diaz G, Cohn A, Fox L, Patel A, Gerber SI, Kim L, Tong S, Lu X, Lindstrom S, Pallansch MA, Weldon WC, Biggs HM, Uyeki TM, Pillai SK, State W, nCo VCIT (2020) First case of 2019 novel coronavirus in the United States. N Engl J Med 382(10):929-936. https://doi. org/10.1056/NEJMoa2001191

44. ASHP (2020) Assessment of evidence for COVID-19-related treatments. https://www.ashp.org/-/media/assets/pharmacy-pract ice/resource-centers/Coronavirus/docs/ASHP-COVID-19-Evide nce-Table. $a$ shx $? 1 \mathrm{a}=$ en \&hash $=\mathrm{B} 414 \mathrm{CC} 64 \mathrm{FD} 64 \mathrm{E} 1 \mathrm{AE} 8 \mathrm{CA} 4$ 7AD753BA744EDF4FFB8C. Accessed 27 March 2020

45. Gautret P, Lagier JC, Parola P, Hoang VT, Meddeb L, Mailhe M, Doudier B, Courjon J, Giordanengo V, Vieira VE, Dupont HT, Honore S, Colson P, Chabriere E, La Scola B, Rolain JM, Brouqui P, Raoult D (2020) Hydroxychloroquine and azithromycin as a treatment of COVID-19: results of an open-label non-randomized clinical trial. Int J Antimicrob Agents. https://doi.org/10.1016/j. ijantimicag.2020.105949

46. Yao X, Ye F, Zhang M, Cui C, Huang B, Niu P, Liu X, Zhao L, Dong E, Song C, Zhan S, Lu R, Li H, Tan W, Liu D (2020) In vitro antiviral activity and projection of optimized dosing design of hydroxychloroquine for the treatment of severe acute respiratory syndrome coronavirus 2 (SARS-CoV-2). Clin Infect Dis. https://doi.org/10.1093/cid/ciaa237 
47. Zhang L, Liu Y (2020) Potential interventions for novel coronavirus in China: A systematic review. J Med Virol 92(5):479-490. https://doi.org/10.1002/jmv.25707

48. Gao J, Tian Z, Yang X (2020) Breakthrough: Chloroquine phosphate has shown apparent efficacy in treatment of COVID-19 associated pneumonia in clinical studies. Biosci Trends 14(1):7273. https://doi.org/10.5582/bst.2020.01047

49. Dong L, Hu S, Gao J (2020) Discovering drugs to treat coronavirus disease 2019 (COVID-19). Drug Discov Ther 14(1):58-60. https://doi.org/10.5582/ddt.2020.01012
50. Casadevall A, Pirofski LA (2020) The convalescent sera option for containing COVID-19. J Clin Invest. https://doi.org/10.1172/ JCI138003

Publisher's Note Springer Nature remains neutral with regard to jurisdictional claims in published maps and institutional affiliations. 